\title{
Temporal Aspects of Vernalization and Flowering in Long-day Storage Onion
}

\author{
Christopher J. D'Angelo and Irwin L. Goldman' \\ Department of Horticulture, University of Wisconsin-Madison, 1575 Linden Drive, Madison, WI \\ 53706
}

\begin{abstract}
AdDitional INDEX WORDs. floral initiation, Allium cepa, bulb onion
Abstract. Vernalization is an important step for floral initiation in onion (Allium cepa), but our understanding of the minimum vernalization time for long-day storage onions to gain floral competence is limited. A series of time course experiments were conducted over 4 years to determine the effects of vernalization time on sprouting, scape emergence, and flowering in 'Cortland', 'Sherman', and CUDH2107. We found an endodormancy period is present in the bulbs of these cultivars that lasts for 8 to 10 weeks. In addition, these three accessions achieve optimum uniform scape emergence after chilling for 14 weeks at $10^{\circ} \mathrm{C}$. On average, when bulbs were chilled for 14 weeks, it took $96.8 \pm$ 15.6 days from planting to flowering in all accessions evaluated. As storage duration under vernalizing temperatures increases, the time to sprouting, scape emergence, and flowering decrease. Furthermore, the variance in time from sprouting to scape emergence was greatly reduced between 10 and 12 weeks of storage for 'Cortland' and CUDH2107, and between 12 and 14 weeks for 'Sherman'. After 10 weeks of chilling, each additional week of storage resulted in an average decrease in time to flowering of $4.1 \%$. We also observed large percentages of bulbs flowering without receiving any vernalization. This observation supports our finding that the relationship between vernalization and flowering in long-day storage onion is facultative rather than obligate. These findings help define the relationship between dormancy, vernalization, and flowering in long-day storage onion.
\end{abstract}

Onion is grown in more than 160 countries (FAO, 2014) and is ranked consistently as the third highest valued vegetable crop in the United States (U.S. Department of Agriculture, 2016). Long-day storage cultivars are used extensively on every continent (Serra, 2002) and are the predominant onion market class in the northern United States (Davie, 2017; Lucier, 2011). These cultivars maintain a high level of quality while in storage for extended periods and are well adapted to the shorter growing seasons of northern climates.

Vernalization, the process during which exposure to cold temperatures over an extended period expedites or induces floral initiation (Chouard, 1960), is an important feature for breeding and producing seed from biennial root vegetables. Onion is biennial and is widely understood to require vernalization to induce flowering. Premature flowering during crop growth, also known as bolting, greatly reduces the quality of storage roots and bulbs, and can render an entire crop unsaleable if present on a large scale. In well-adapted cultivars, the minimum length of vernalization required for flowering, or the critical vernalization period, is long enough that a brief period of vernalizing temperatures does not result in bolting. Thus, vernalization serves a protective role against bolting during bulb production. However, seed producers and plant breeders also wish to understand and manipulate vernalization to achieve consistent, uniform flowering each year.

The path to floral initiation in onion is complicated. Extensive work on the molecular basis of vernalization and flowering in Arabidopsis thaliana, sugar beet (Beta vulgaris), and temperate grasses such as oats (Avena sativa), wheat (Triticum aestivum), rye (Secale cereale), and barley (Hordeum

Received for publication 5 July 2018. Accepted for publication 18 Sept. 2018. We thank Ned, John, and Joan Crescio of Jack's Pride Farms in Randolph, WI, for their assistance and for donating the bulbs used in this study.

${ }^{1}$ Corresponding author. Email: ilgoldma@wisc.edu. vulgare) have demonstrated that the mechanisms for vernalization and flowering are not conserved across orders (Bouché et al., 2017). Discovery of the FLOWERING LOCUS T (FT)-like gene $A c F T 2$, with an upregulation that correlates highly with vernalization-induced flowering, provided evidence that onion is dissimilar from other well-characterized monocot flowering pathways (Bouché et al., 2017; Lee et al., 2013).

Much of the published research on onion vernalization has focused on identifying conditions under which vernalization occurs. Temperatures ranging from 2 to $17{ }^{\circ} \mathrm{C}$ can result in vernalization, with an optimum between 7 and $12{ }^{\circ} \mathrm{C}$ (Wiebe, 1990). Shishido and Saito (1977) and Brewster (1983) have proposed the minimum size in which bulbs and seedlings are responsive to chilling. These studies have played an important role in defining the conditions for vernalization in onion, particularly as seedlings or sets, but do not describe the length of vernalization required to achieve uniform flowering in longday bulbs.

Vernalization can be accomplished during both the seedling and bulb stages. Efforts to vernalize onion seedlings began as early as 1945 with both the intent of controlling bolting and accelerating flowering for seed production (Heath, 1945). Seedling vernalization involves exposing young plants to vernalizing temperatures before bulbing to induce flowering. Early attempts at vernalizing seedlings were met with mixed results until the discovery that seedlings must pass a juvenile phase before they are receptive to chilling (Holdsworth and Heath, 1950). The juvenile phase is cultivar dependent and can range from the 4- to 14-leaf stage, after which the plants are vernalized for $\approx 60$ d (Khokhar, 2014; Rabinowitch, 1985; Shishido and Saito, 1976). Although seedling vernalization is a useful tactic for producing seed rapidly, and it has applications in marker-assisted selection and backcrossing, there are limitations for its use in phenotypic selection of bulb traits because this procedure does not allow for evaluation of the 
mature bulb. In addition, such a procedure may favor boltingsusceptible genotypes, which may not be preferred in breeding programs.

A meta-analysis using vernalization experiments published between 1963 and 1983 was used to create a vernalization model for onion (Streck, 2003). This model confirmed the previously published optimum vernalization temperature of $10{ }^{\circ} \mathrm{C}$ and reported that vernalization is complete after $60 \mathrm{~d}$ of chilling. Although this analysis made use of data from Japanese, American, and Brazilian onion cultivars, only the Brazilian cultivars were evaluated as bulbs; the Japanese and American cultivars were vernalized as seedlings. Vernalization requirements for seedlings cannot necessarily be translated to bulbs, in part because of the presence of bulb endodormancy in many onion cultivars. Bulb endodormancy is observed at harvest and can last from weeks to months, depending upon the genotype (Carter et al., 1999). Because onion seedlings are vernalized while they are actively growing, the effects of dormancy are not factored into seedling vernalization models. Despite some information on optimal vernalization conditions and endodormancy, the temporal aspects of vernalization and flowering in long-day onion bulbs have not been investigated.

Through this study, we sought to quantify the temporal aspects of vernalization in long-day storage onions and to gain an understanding of the relationship between vernalization and flowering. A series of time course experiments were conducted over 4 years with $\mathrm{F}_{1}$ hybrid and doubled haploid onion bulbs stored at $10{ }^{\circ} \mathrm{C}$ for varying lengths of time. We characterized vernalization and dormancy in long-day storage onion bulbs for cultivars that were representative of the material grown in Wisconsin.

\section{Materials and Methods}

Time COURSE EXPERiments. A series of time course experiments were conducted between 2013 and 2016 to determine the critical vernalization period and optimum chilling time for long-day onion. The $\mathrm{F}_{1}$ hybrid cultivar Cortland (Bejo Seeds, Oceano, CA) was used for field experiments in 2013. In 2014, the experiment was expanded to include both 'Cortland' and the $F_{1}$ hybrid 'Sherman' (Bejo Seeds). In 2015 and 2016, the experiment was repeated with a robust doubled haploid line, CUDH2107 (Alan et al., 2004), and was grown in two environments. The field design was unreplicated in 2015 , but included two replications per location in 2016. All accessions were grown from seed on muck soil under commercial growing conditions at Jack's Pride Farms in Randolph, WI. An additional site in Markesan, WI, was used as a second location in 2015 and 2016. Seed was planted at a density of 36 plants $/ \mathrm{m}$ using a modified seeder (Planet Junior; Cole Planter Co., Albany, GA) planter equipped with a cone seeder attachment in $3.66-\mathrm{m}$ rows with a $1.22-\mathrm{m}$ alley and $30-\mathrm{cm}$ row spacing. No maleic hydrazide or other sprout inhibitors were applied to the plants in the field. All bulbs were topped in the field, harvested in early September, and cured for 1 week in a dark, wellventilated storage room at ambient temperature. Cured bulbs were transferred to a small growth chamber (model I-35LLVL; Percival Manufacturing Co., Perry, IA) and held without lights at $10{ }^{\circ} \mathrm{C}$ to chill. After an assigned period of chilling, 12 bulbs of each cultivar were removed from the growth chamber and planted in the greenhouse. This procedure was repeated every 2 weeks from 4 to 28 weeks of chilling in 2013 and 2014. In 2015 and 2016, five bulbs from each location and replication were planted every 2 weeks. The 2015 experiment ranged from 2 to 28 weeks whereas the 2016 experiment ranged from 0 to 28 weeks.

Critical Vernalization Period. The critical vernalization period was defined as the minimum number of days of chilling at $10{ }^{\circ} \mathrm{C}$ required for $100 \%$ of the bulbs that sprouted to produce scapes. The optimum chilling time was defined as the shortest storage duration at $10{ }^{\circ} \mathrm{C}$ required for early, uniform scape emergence across all accessions, years, and environments. Uniform scape emergence was defined as having an SD 10 or less for the number of days from sprouting until scape emergence.

Greenhouse CUlture. All bulbs were planted in plastic pots in a medium composed of a 2:1 mix of silty loam compost soil collected from the West Madison Agricultural Research Station (Arlington, WI) and soilless medium (MetroMix; Sun Gro Horticulture, Agawam, MA). The greenhouse temperature in 2013-14 was kept at $16^{\circ} \mathrm{C}$ using steam baseboard radiators and a combination of manual and automated vents. In 2015-16, airconditioned greenhouses with forced-air heating were used to maintain a temperature of $20{ }^{\circ} \mathrm{C}$. In all years, high-pressure sodium supplemental lighting was used to maintain a 16-h daylength with a photon flux density of $103 \mu \mathrm{mol} \cdot \mathrm{m}^{-2} \cdot \mathrm{s}^{-1}$ in 2013-14, and $343 \mu \mathrm{mol} \cdot \mathrm{m}^{-2} \cdot \mathrm{s}^{-1}$ in 2015 and 2016 (model QMSS; Apogee Instruments, Logan, UT). Plants were watered as needed daily and were fertilized as needed with a $400-\mathrm{mg} \cdot \mathrm{L}^{-1}$ solution of $20 \mathrm{~N}-4.365 \mathrm{P}-16.602 \mathrm{~K}$ fertilizer with micronutrients (Peters Professional Peat-Lite Special; ICL Speciality Fertilizers, Dublin, $\mathrm{OH}$ ).

Data collection. Individual plants were monitored for sprouting, scape emergence, and flowering. Observations were made every few days (Table 1). Sprouting was defined as the presence of green leaf tissue emerging from the neck of the bulb. Scape emergence was defined as the presence of the spathe from a leaf sheath at the crown of the plant. Flowering was defined as the opening of the spathe to reveal unopened flowers in the inflorescence (Fig. 1). The date was recorded on initial observation of each physiologic event. The number of days from planting to sprouting, scape emergence, and flowering was calculated from the recorded dates. Days to conversion was derived from the difference in days from sprouting to scape emergence, and represents the time required to convert from vegetative to reproductive growth. In addition, the number of days from scape emergence to flowering was calculated.

WeEkLY dissection. Bulb dissections were performed upon removal from the cooler in 2013, 2015, and 2016 at regular intervals to monitor for physiologic changes inside the bulb. One randomly selected 'Cortland' onion bulb was dissected each week in 2013. In 2015-16, three CUDH2107 bulbs per location and replication were dissected every 2 weeks. Bulb cross-sections were photographed and inspected for physiologic changes at the meristem and evidence of floral development.

Statistical analysis. Analysis of variance (ANOVA) with type III sums of squares was performed on data from each physiologic event across all treatments using the "car" package in $\mathrm{R}$ ( $\mathrm{R}$ Development Core Team, 2018). A square root transformation was applied to all sprouting data, whereas natural logarithmic transformations were performed on all scape emergence, flowering, days to conversion, and days from scape emergence to flowering data to satisfy normality and 
Table 1. Mean and SD of the number of days between observations for each experimental year for onion plants grown in greenhouse conditions in Madison, WI, after removal from vernalizing temperatures at different intervals. The total number of days when sprouting, scape emergence, or flowering was observed is indicated in the column on the right.

\begin{tabular}{lcc}
\hline Yr & $\begin{array}{c}\text { Time between recorded } \\
\text { observations }[\text { mean } \pm \text { SD }(d)]\end{array}$ & Total observation dates (no.) \\
\hline 2013 & $2.45 \pm 1.79$ & 70 \\
2014 & $1.82 \pm 1.71$ & 123 \\
2015 & $3.38 \pm 2.71$ & 72 \\
2016 & $2.39 \pm 1.70$ & 91
\end{tabular}
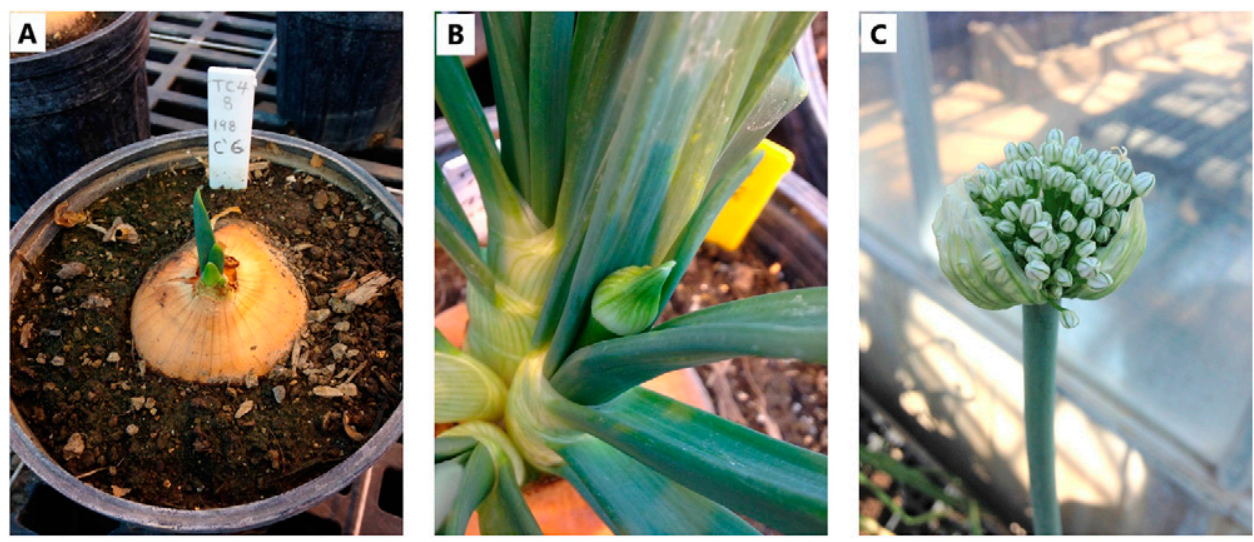

Fig. 1. Scoring criteria for evaluation of (A) initial sprouting, (B) scape emergence, and (C) flowering under greenhouse conditions for onion plants removed from vernalizing temperatures at different time periods. For calculate the number of days from planting to each stage as well as the number of days between stages. each onion plant, the date was recorded when each physiologic stage was first observed. These dates were used to

small ( $\approx 5 \%$ or less) in every case except days to sprouting for 'Cortland' (19.7\%). By contrast, eta squared values were greatest for storage duration across all metrics and ranged from $41 \%$ to $86 \%$ in 'Cortland' and CUDH2107. 'Sherman' was evaluated only in 2014 , thus the year effect was not assessed in the model. Bulb diameter is also a significant term in three of five metrics for CUDH2107, but the small effect size ( $\approx 1 \%$ or less) minimizes its importance in the model.

After 10 weeks in the cooler, each additional week of chilling CUDH2107 bulbs results in a $4.1 \%$ reduction, on average, in the time to flowering and a 3\% reduction in the number of days to conversion. Similarly, on average, each additional centimeter in bulb diameter reduces the time to flowering by $3.8 \%$ and the number of days to conversion by $4.8 \%$. In 'Cortland', each additional week of chilling averages a $7.4 \%$ reduction in days to conversion and a $4.7 \%$ reduction in days to flowering. For 'Sherman', each additional week of chilling averages a $6.6 \%$ reduction in the number of days to homoskedasticity assumptions for ANOVA. Linear models for all CUDH2107 data were constructed using a reduced dataset ranging from 10 to 28 weeks in the cooler to include only timepoints with uniform scape emergence. As a result of the doubled haploid's extreme response to chilling, the days to scape emergence and days to conversion data in CUDH2107 had a bimodal distribution. By analyzing the post-10 weeks of chilling samples separately, the data could be fit to a linear model and satisfied all the assumptions for ANOVA. The full datasets were used to construct the linear models for both 'Cortland' and 'Sherman'. Individual bulbs were treated as experimental units in 'Cortland' and 'Sherman', with replication over time in 'Cortland'. Measuring individual bulbs allowed us to assess the response of bulb-to-bulb variation to increasing chilling lengths. In addition, although the evaluation of CUDH2107 in 2016 included two replications per environment, the replication term was not significant for any of the metrics and was dropped from the model. This allowed the CUDH2107 data from 2015 and 2016 to be combined into a single model for analysis. Effect sizes were measured using an eta squared calculation from the "sjstats" package in R (R Development Core Team, 2018).

\section{Results}

Time COURSE EXPERIMENT. ANOVA revealed a highly significant effect of storage duration $(P \leq 0.001)$ on all traits and accessions evaluated in this study (Tables $2-4$ ). The year effect was also a significant model term in many of the metrics; however, eta squared calculations indicate that the effect size is conversion and a $5.3 \%$ reduction in days to flowering.

For all cultivars, a strong negative relationship can be seen for sprouting, scape emergence, flowering, and days to conversion as storage durations at $10^{\circ} \mathrm{C}$ increase (Figs. 2-5). We found significant $(\alpha \leq 0.05)$ differences in both mean and variance for time to conversion between 10 and 14 weeks of chilling for 'Cortland' in 2013 and 'Sherman' in 2014 (Fig. 3D), and between 8 and 14 weeks of chilling for 'Cortland' in 2014 (Fig. 2D). We also found very significant $(\alpha \leq 0.001)$ differences in variance for time to conversion between 10 and 12 weeks of chilling for CUDH 2107 in 2015 and 2016 (Figs. 4D and 5D). Overall, these relationships are relatively stable across years and environments but are more clearly defined in the doubled haploid than in the $\mathrm{F}_{1}$ hybrids.

Further differences between CUDH2107 and the hybrid cultivars can be found in the number of days from scape emergence to flowering. For both 'Cortland' (Fig. 2E) and 'Sherman' (Fig. 3E), the slope of this measurement as time in the cooler increases is negative but shallow, whereas the distribution for CUDH2107 over time is right skewed, with peaks at 10 weeks in 2015 (Fig. 4E) and between 10 and 16 weeks in 2016 (Fig. 5E). Despite these differences, increasing the duration of cold storage decreased the required greenhouse time to observe uniform scape emergence in all cultivars (Figs. $2 \mathrm{~F}, 3 \mathrm{~F}, 4 \mathrm{~F}$, and $5 \mathrm{~F}$ ).

By 12 weeks of cold storage, all cultivar and year combinations reached $100 \%$ conversion from a vegetative to a reproductive phase within a given storage duration. However, the bulbs reached $\approx 80 \%$ conversion in as few as 4 to 6 weeks of cold storage. For 2014, both 'Cortland' and 'Sherman' had 
Table 2. Degrees of freedom (df) and F values from analysis of variance (ANOVA) for reproductive traits from 10 to 28 weeks of vernalizing temperatures for 'Cortland' onion bulbs grown in greenhouse conditions. The bulbs were grown in Randolph, WI, in 2013 and 2014 and were evaluated in a greenhouse during the postharvest period using a completely randomized design.

\begin{tabular}{|c|c|c|c|c|c|c|c|c|c|c|c|c|c|c|c|}
\hline \multirow{3}{*}{$\begin{array}{l}\text { ANOVA } \\
\text { Source } \\
\text { Year }\end{array}$} & \multicolumn{3}{|c|}{$\begin{array}{l}\text { Time to } \\
\text { sprouting }\end{array}$} & \multicolumn{3}{|c|}{$\begin{array}{l}\text { Time to scape } \\
\text { emergence }\end{array}$} & \multicolumn{3}{|c|}{$\begin{array}{l}\text { Time to } \\
\text { flowering }\end{array}$} & \multicolumn{3}{|c|}{$\begin{array}{l}\text { Time from sprouting } \\
\text { to scape emergence }\end{array}$} & \multicolumn{3}{|c|}{$\begin{array}{c}\text { Time from scape } \\
\text { emergence to flowering }\end{array}$} \\
\hline & \multirow{2}{*}{$\frac{\mathrm{df}}{1}$} & \multicolumn{2}{|c|}{$\mathrm{F}$} & \multirow{2}{*}{$\begin{array}{r}\mathrm{df} \\
1\end{array}$} & \multicolumn{2}{|c|}{$\mathrm{F}$} & \multirow{2}{*}{$\begin{array}{r}\mathrm{df} \\
1\end{array}$} & \multicolumn{2}{|c|}{$\mathrm{F}$} & \multirow{2}{*}{$\frac{\mathrm{df}}{1}$} & \multicolumn{2}{|c|}{$\mathrm{F}$} & \multirow{2}{*}{$\begin{array}{r}\text { df } \\
1\end{array}$} & \multicolumn{2}{|c|}{$\mathrm{F}$} \\
\hline & & 38.3 & $* * *$ & & 9.8 & $* *$ & & 0.5 & & & 0.0 & & & 11.6 & $* * *$ \\
\hline Year:weeks in cooler & 12 & 4.0 & $* * *$ & 12 & 3.0 & $* * *$ & 12 & 4.5 & $* * *$ & 12 & 3.6 & $* * *$ & 12 & 4.4 & $* * *$ \\
\hline Residuals & 284 & & & 262 & & & 242 & & & 262 & & & 241 & & \\
\hline
\end{tabular}

**,***Significant at $P<0.01$ or 0.001 , respectively.

Table 3. Degrees of freedom (df) and F values from analysis of variance (ANOVA) for reproductive traits from 10 to 28 weeks of vernalizing temperatures for 'Sherman' onion bulbs grown in greenhouse conditions. The bulbs were grown in Randolph, WI, in 2013 and 2014 and were evaluated in a greenhouse during the postharvest period using a completely randomized design.

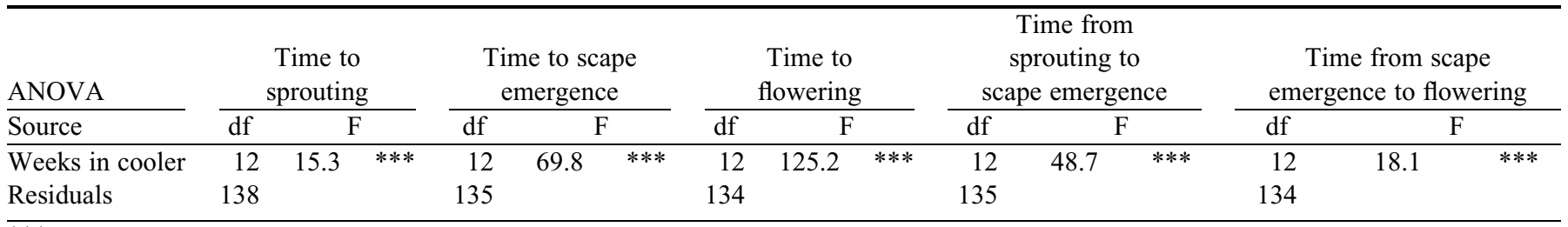

$* * * P<0.001$.

Table 4. Degrees of freedom (df) and F values from analysis of variance (ANOVA) for reproductive traits from 10 to 28 weeks of vernalization for the doubled haploid onion accession CUDH2107. The bulbs were grown in Randolph and Markesan, WI, in 2015 and 2016 and were evaluated in a greenhouse during the postharvest period using a randomized complete block design.

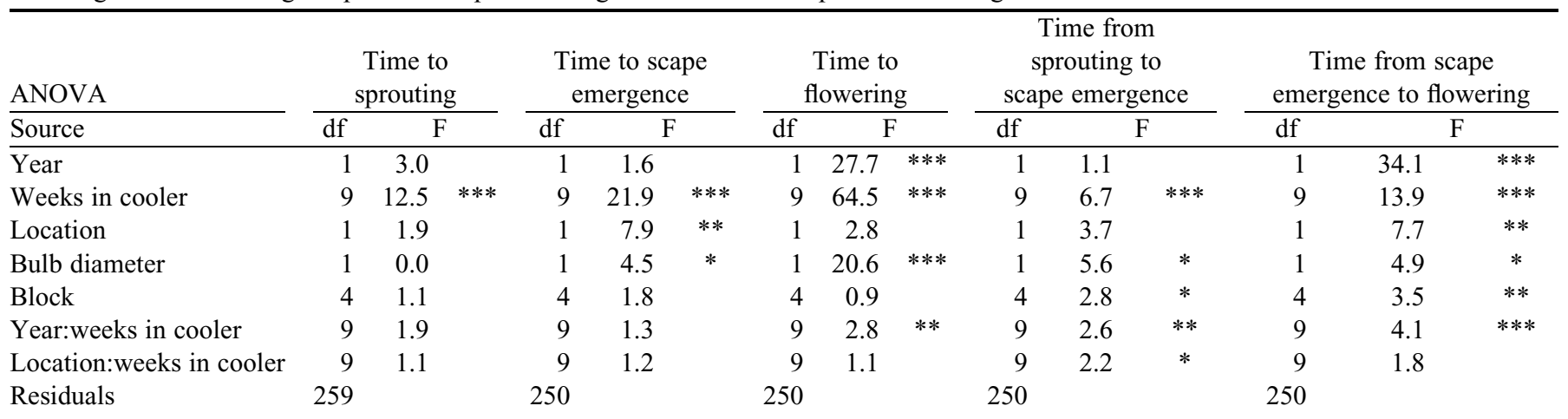

*, **, ***Significant at $P<0.05,0.01$, or 0.001 , respectively.

$100 \%$ conversion from the outset, with only 4 weeks of chilling; in 2016, CUDH2107 had 90\% conversion without any vernalization.

DormanCY. Signs of bulb endodormancy were observed in all accessions and years of this study; they are best documented in 'Cortland' and CUDH2107. Little evidence of visible growth, such as rooting or sprouting, occurred for the first 7 weeks after planting in 'Cortland' or for the first 5 to 6 weeks in CUDH2107 (Fig. 6A). As bulbs in the greenhouse first showed signs of growth, bulbs that remained in cold storage began to show signs of breaking dormancy. This included pressing of the basal plate, when the basal plate begins to protrude from the bulb; swelling of root initials around the basal plate; and a visual yellowing of the immature leaves inside the bulb (Fig. 6B). All bulbs, whether in cold storage or the greenhouse, showed signs of visible growth after 9 weeks after curing for 'Cortland' and between 8 and 10 weeks for CUDH2107. The first evidence of floral development within a bulb during cold storage was observed in 'Cortland' after 28 weeks of chilling during a dissection of a bulb from the 2013 field season (Fig. 6C). A small, yellow and white immature scape was observed originating from the basal plate. This was the only immature scape that we identified throughout the bulb dissections in 'Cortland' and CUDH2107.

\section{Discussion}

Onions have been described as obligate vernalizing plants that require exposure to vernalizing temperatures to flower (Wiebe, 1990). To our knowledge, the minimum length of vernalization for flowering to occur, known as the critical vernalization period, has not been reported previously for longday storage onion bulbs. Through these experiments, we found that the critical vernalization period for 'Cortland' is 10 weeks, 12 weeks for CUDH2107, and 4 weeks or less for 'Sherman'. However, on a percentage basis, we observed scape emergence 

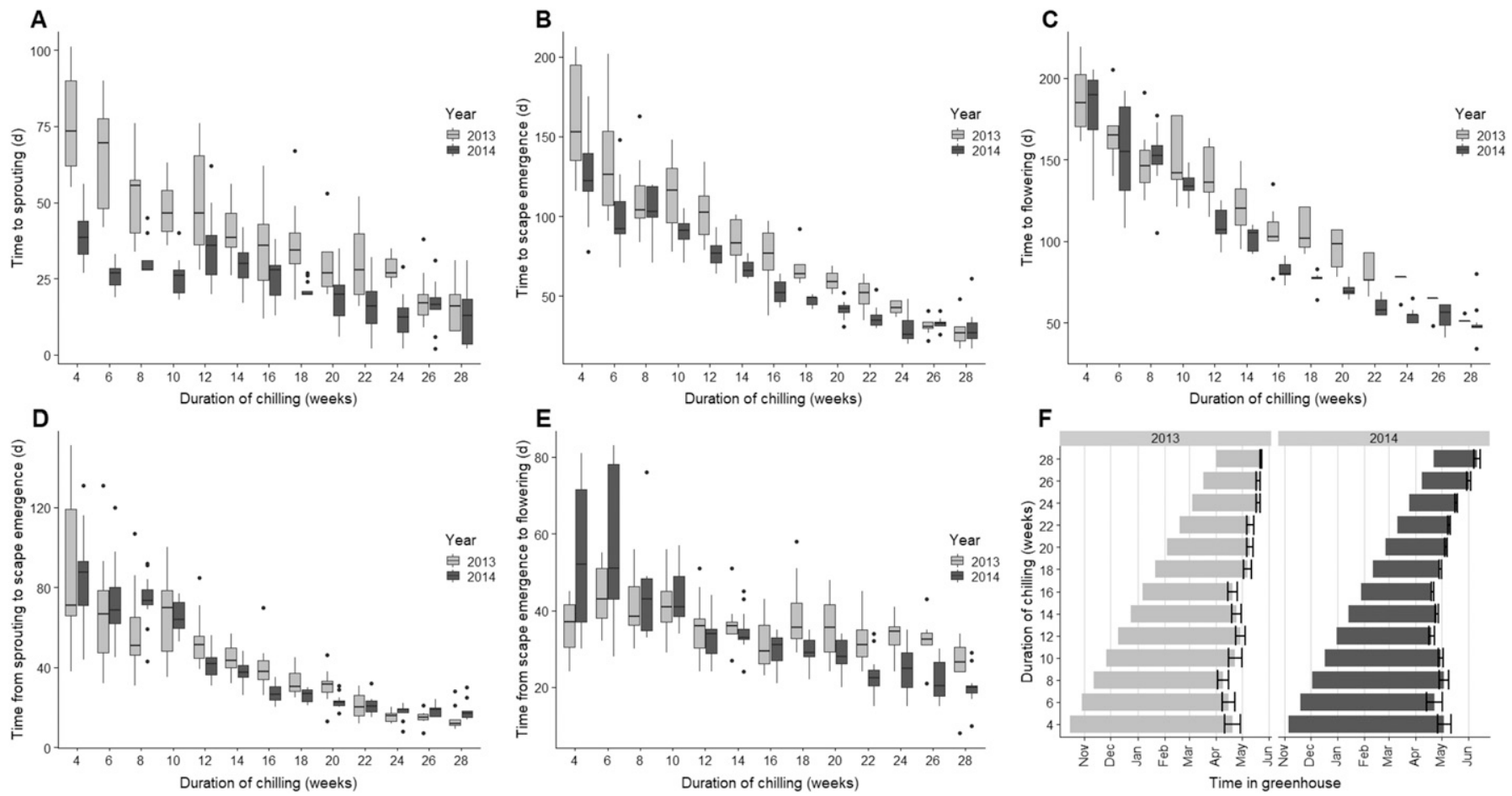

Fig. 2. Response of onion cultivar Cortland to postharvest storage in 2013-14 for the number of days from planting in the greenhouse to (A) initial sprouting, (B) scape emergence, and (C) flowering, as well as the number of days from (D) sprouting to scape emergence (days to conversion) and (E) scape emergence to flowering. (F) Gantt chart indicating the time spent in the greenhouse from planting through flowering. The left side of each bar shows the planting date whereas the right side indicates the date the flowering was first observed. The error bars represent the standard error. The dots on the boxplots are potential outliers that fell outside of 1.5 times the interquartile range.
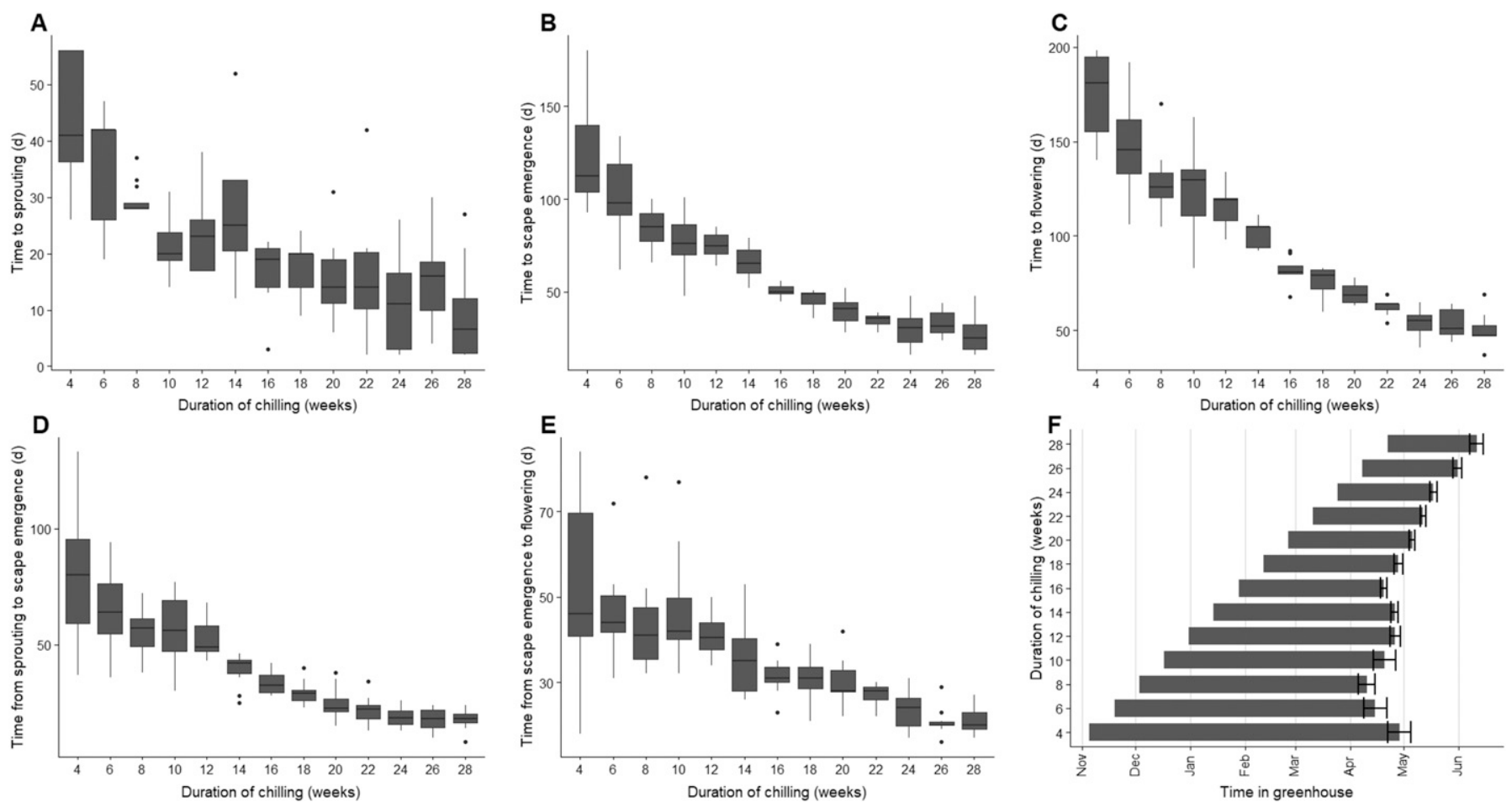

Fig. 3. Response of onion cultivar Sherman to postharvest storage in 2013-14 for (A) the number of days from planting in the greenhouse to initial sprouting, (B) the number of days from planting in the greenhouse to initial scape emergence, $(\mathbf{C})$ the number of days from planting in the greenhouse to initial flowering, (D) the number of days from sprouting to scape emergence (days to conversion), and (E) the number of days from scape emergence to flowering. (F) Gantt chart indicating the time spent in the greenhouse from planting through flowering. The left side of each bar shows the planting date whereas the right side indicates the date the flowering was first observed. The error bars represent the standard error. The dots on the boxplots are potential outliers that fell outside of 1.5 times the interquartile range. 

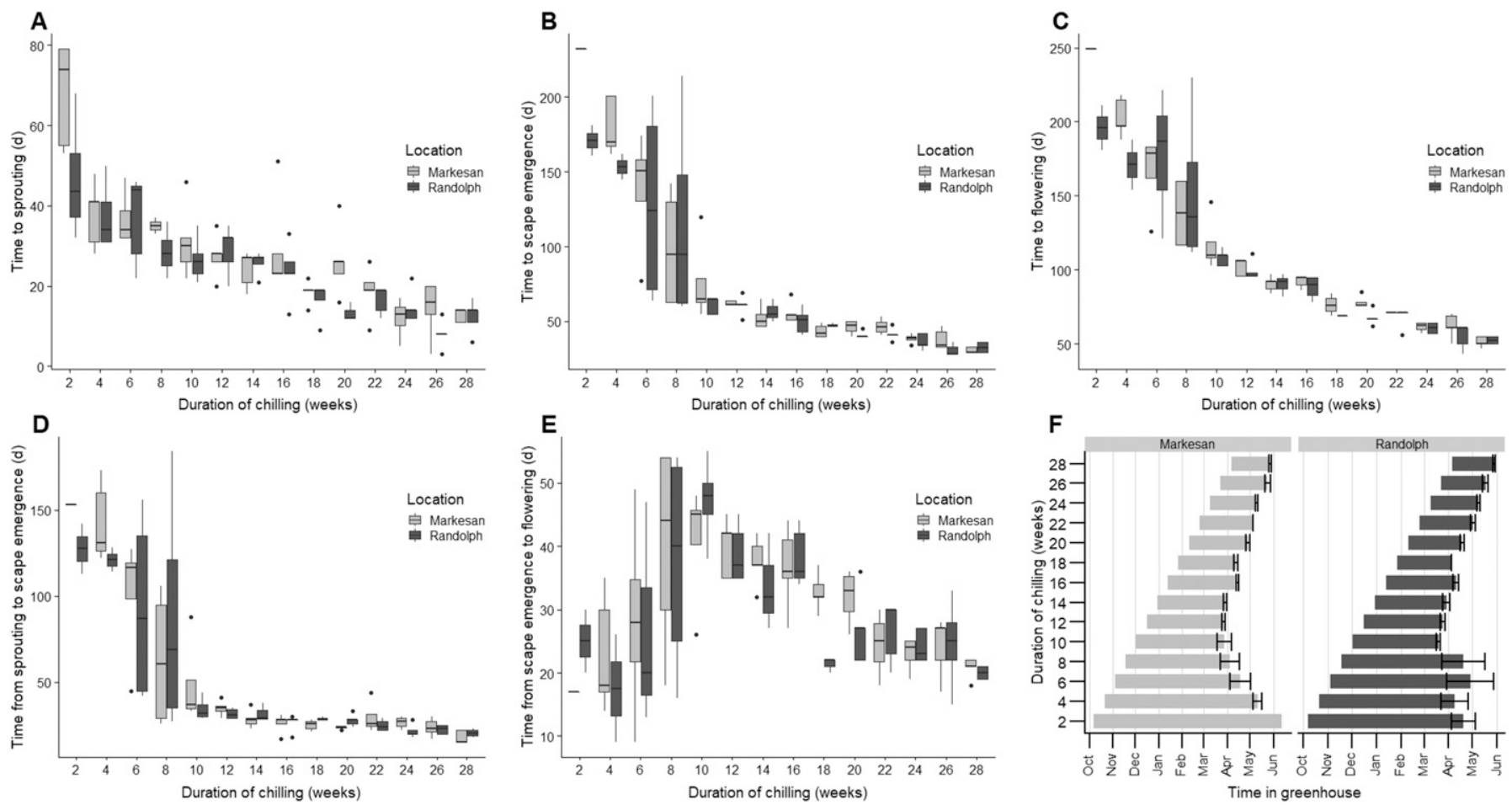

Fig. 4. Response of onion accession CUDH2107 to postharvest storage in 2015-16 from bulbs grown at two Wisconsin locations, Markesan and Randolph, for (A) the number of days from planting in the greenhouse to initial sprouting, $(\mathbf{B})$ the number of days from planting in the greenhouse to initial scape emergence, $(\mathbf{C})$ the number of days from planting in the greenhouse to initial flowering, (D) the number of days from sprouting to scape emergence (days to conversion), and (E) the number of days from scape emergence to flowering. (F) Gantt chart indicating the time spent in the greenhouse from planting through flowering. The left side of each bar shows the planting date whereas the right side indicates the date the flowering was first observed. The error bars represent the standard error. The dots on the boxplots are potential outliers that fell outside of 1.5 times the interquartile range.
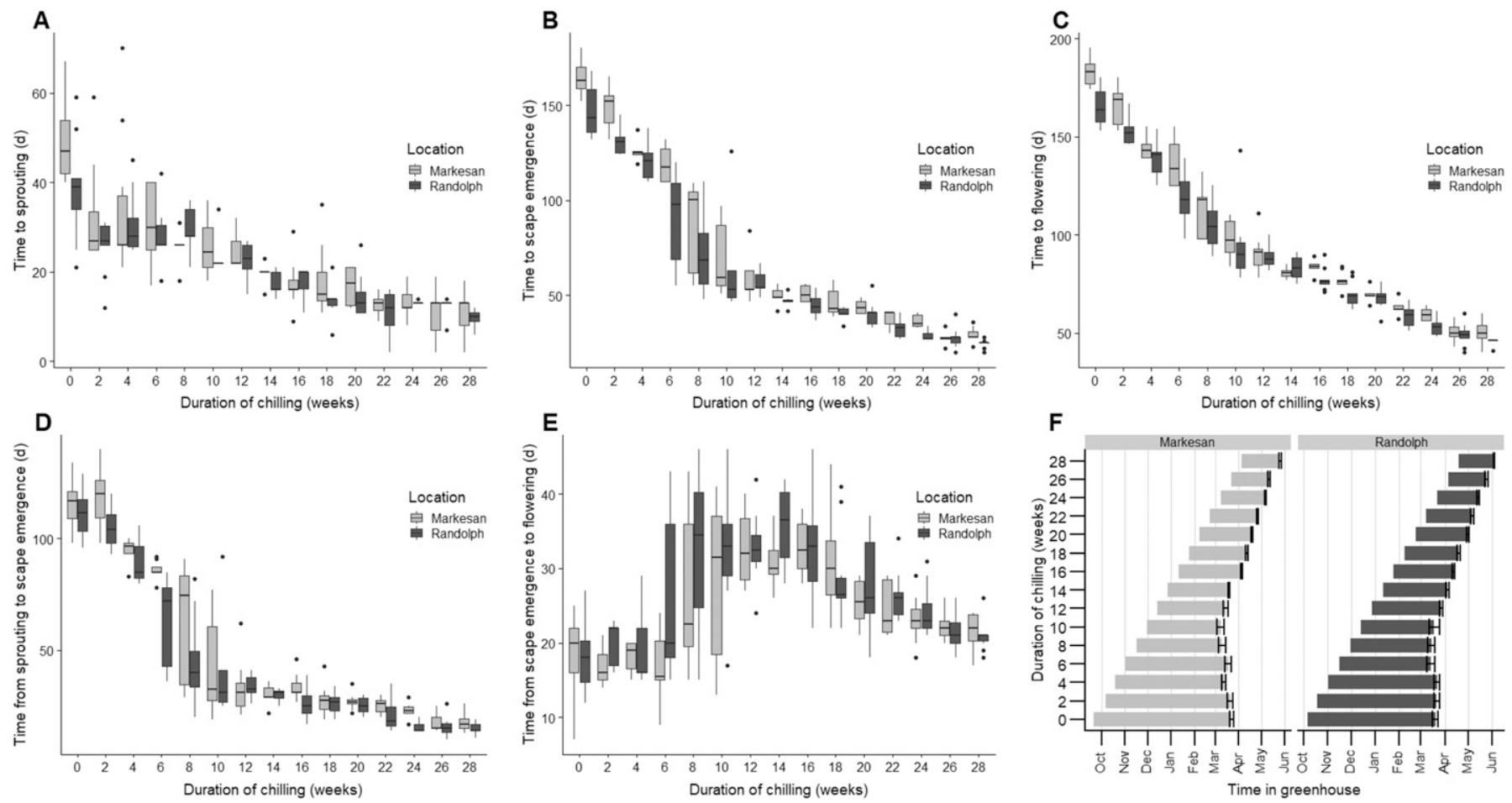

Fig. 5. Response of onion accession CUDH2107 to postharvest storage in 2015-16 from bulbs grown at two Wisconsin locations, Markesan and Randolph, for (A) the number of days from planting in the greenhouse to initial sprouting, (B) the number of days from planting in the greenhouse to initial scape emergence, $(\mathbf{C})$ the number of days from planting in the greenhouse to initial flowering, (D) the number of days from sprouting to scape emergence (days to conversion), and (E) the number of days from scape emergence to flowering. (F) Gantt chart indicating the time spent in the greenhouse from planting through flowering. The left side of each bar shows the planting date whereas the right side indicates the date the flowering was first observed. The error bars represent the standard error. The dots on the boxplots are potential outliers that fell outside of 1.5 times the interquartile range. 

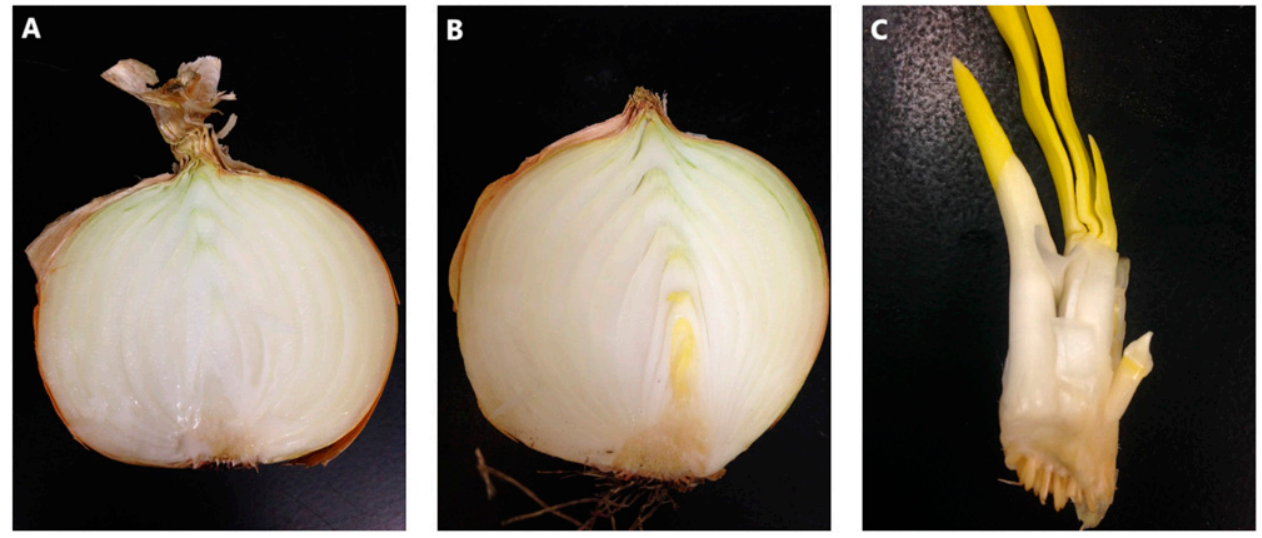

sprouting, scape emergence, and flowering. The days to conversion is also hastened with increased chilling, as indicated by the decrease in mean and variance of days from sprouting to scape emergence (Figs. 2D, 3D, 4D, and 5D). On average, the days to conversion for 'Cortland' and 'Sherman' were reduced by $6.6 \%$ and $7.4 \%$, respectively, for each additional week of chilling. In the linear models, storage duration had the greatest effect on all metrics and explained $41 \%$ to $85 \%$ of the model variance, which indicates

Fig. 6. Photographs of onion cultivar Cortland bulbs grown in greenhouse conditions following various storage durations. (A) At 2 weeks of cold storage, bulbs show no signs of growth near the meristem or basal plate. (B) After 11 weeks in the cooler, bulbs begin to show signs that dormancy is broken. These include a yellowing of the leaf initials, pressing of the basal plate, and swollen root initials around the basal plate. (C) A newly formed scape found inside a bulb after 28 weeks of cold storage. Also note the length of the young leaves and roots as well as the formation of discrete leaf sheaths.

and flowering across all cold-storage treatment groups, including $90 \%$ of the bulbs in the 0 week treatment in 2016, which were not exposed to vernalizing temperatures.

Defining the critical vernalization period based on percentage of flowering is problematic because it is dependent on the termination date of the experiment and does not explain differences in variance between storage durations. Our observations suggest that the notion of a critical vernalization period is inadequate for describing the relationship between vernalization and flowering in 'Cortland', 'Sherman', and CUDH2107. We propose that a more informative metric is the optimum chilling time, which we defined as the storage duration that results in the earliest uniform flowering across all accessions. We found the optimum chilling time at $10{ }^{\circ} \mathrm{C}$ for these three accessions to be 14 weeks (Figs. 2-5). On average, at 14 weeks it took $96.8 \pm 15.6 \mathrm{~d}$ from planting to flowering in all accessions evaluated. When planted in early January in the greenhouse, this resulted in an initial flowering date between mid March and mid April (Figs. 2F, 3F, 4F, and 5F). Observing individual bulbs was key to this finding because it allowed us to assess variation both within and among treatment groups. Based on the uniformity and relative earliness of flowering at 14 weeks of chilling, we consider this storage duration to be the optimum chilling length for these three long-day onion accessions. Identifying the optimum storage duration is an important step in defining the conditions necessary for off-season growth, such as in a winter greenhouse. Bulbs stored under optimum conditions will result in rapid, uniform flowering, which is essential for controlled-environment seed production and is a key component of an annual cycle breeding system in onion.

Because we observed flowering at all storage durations, we find little evidence to suggest that the relationship between vernalization and flowering in long-day onion is obligate. This relationship has been described in seed production of short-day cultivars, such as N-53, Agrifound Dark Red and Arka Kalyan, during which bulbs are cured for $15 \mathrm{~d}$ after harvest and are replanted immediately for seed production without prior vernalization (Currah and Proctor, 1990). Rather, these data suggest the response to vernalization in long-day onion bulbs is facultative. As the storage duration at $10{ }^{\circ} \mathrm{C}$ increases, there is a significant improvement in both the time to and uniformity of because all the bulbs used in these experiments were between 3.6 and $6.4 \mathrm{~cm}$ in diameter, which is larger than the $1.5-\mathrm{cm}$ minimum bulb diameter required for floral competence (Heath, 1945).

Although we found 14 weeks of storage to be the optimum, there are applications that may benefit from longer periods of chilling. Increased chilling leads to a reduction in the overall time from planting to flowering, which in turn translates to less time required in the greenhouse. Shorter periods of greenhouse use have implications for pest and disease management, resource allocation, and experimental design. Some cultivars have a wide range of storage durations that yield similar initial flowering dates. In 'Sherman', bulbs stored between 12 and 18 weeks flowered at about the same time in mid to late April (Fig. 3F). Likewise, 'Cortland' bulbs stored between 12 and 16 weeks had similar flowering dates (Fig. 2F). In both examples, bulbs that were chilled longer required less time in the greenhouse but had similar initial flowering dates. By contrast, the storage window for early flowering in CUDH2107 is much smaller and only spans from 12 to 14 weeks (Figs. 4F and 5F). After 14 weeks, additional time in the cooler delays the initial flowering date.

For the first 8 to 10 weeks of each evaluation, all accessions showed signs of dormancy followed by a uniform resurgence of growth, both in the greenhouse and in the cooler. This observed break in dormancy seems to be correlated with substantial reductions in the mean and variance of the time to conversion, and suggests that dormancy may have an impact on the uniformity of flowering before dormancy release. This raises the question of whether the presence of dormancy influences the rate of vernalization and flowering. Breaking of dormancy and uniform flowering may require 10 and 14 weeks, respectively, but only 4 of these weeks may be contributing to the vernalization response. This hypothesis is also supported by the findings of Shishido and Saito (1977), who found that bulbs put into cold storage at 0 or $30 \mathrm{~d}$ after harvest require a longer period of chilling than bulbs chilled $52 \mathrm{~d}$ after harvest. If dormancy and vernalization are mutually exclusive, or if dormant bulbs are vernalized at a slower rate than nondormant bulbs, then the true optimum chilling time in the absence of dormancy may be substantially less than 14 weeks. This could account for the discrepancy between our findings and those of 
the previously reported onion vernalization model, which relied heavily on seedling data and found that full vernalization is achieved in 60 effective vernalization days, or $\approx 8.6$ weeks (Streck, 2003).

There may be factors other than vernalization that trigger floral initiation. In 2016, scapes emerged in $90 \%$ of the CUDH2107 bulbs from the 0-week treatment group, which did not receive any chilling. These plants were grown in a $20{ }^{\circ} \mathrm{C}$ greenhouse with forced-air heating, air conditioning, and supplemental lighting. Similarly, flowering was observed in all accessions, years, and storage durations. Vernalization is not the only path to flowering, but its impact on flowering time is substantial. The literature on the effects of daylength on floral initiation has been inconclusive, but it is possible that light quality plays a role. Despite maintaining a 16-h daylength with high-pressure sodium lighting, many of the plants from several different storage durations flowered within a short period of each other. This suggests there could be an additional environmental cue for floral initiation other than temperature or daylength. Brewster (1983) tested the effects of photon flux density and the red:far-red ratio on floral initiation in onion across different daylengths and found that a combination of low photon flux density and red:far-red ratio is more effective for floral initiation than a high photon flux density and red:far-red ratio. There are cyclical changes in the red:far-red ratio of natural light throughout the year, with the lowest ratio occurring in the early spring, near the time when we began seeing scape emergence in plants from the lowest storage duration groups (Gorski, 1980). If a low red:far-red ratio serves as a cue for floral initiation, then the quality of natural light could have an impact on plant growth in a glass greenhouse, even with supplemental lighting.

It is likely that the time from scape emergence to flowering can be further influenced by greenhouse conditions following scape emergence. As shown by Brewster (1983), parameters such as temperature, light intensity, and photoperiod can be altered to impact scape growth. Increasing these conditions after scape emergence may increase the rate of scape elongation and reduce the time from scape emergence to flowering; however, increasing both the temperature and daylength comes at the risk of promoting bulbing. The response to temperature and photoperiod during the competition phase can vary by genotype, so the balance between warm temperatures and long daylengths must be managed accordingly (Brewster, 1983).

Onion floral development is a complex process influenced by both internal and external factors. By characterizing bulb dormancy and vernalization in the context of floral initiation, we were able to define the facultative nature of vernalization in three long-day onion accessions and to identify the optimum storage duration for early uniform flowering in these accessions. Further analysis of more diverse onion accessions is warranted to determine whether this conclusion is characteristic of long-day onion in general. This study provides some of the first evidence of the potential facultative nature of vernalization in onion. Although it is clear that vernalization is of great importance for onion seed production and it provides uniformity in flowering, its role in the conversion from the vegetative phase to the reproductive phase may have been previously overstated. Results from this work revealed optimal storage durations for long-day onions that might be used by plant breeders and seed producers to enhance the efficiency and productivity of onion's reproductive phase (Shishido and Saito, 1977).

\section{Literature Cited}

Alan, A.R., A. Brants, E. Cobb, P.A. Goldschmied, M.A. Mutschler, and E.D. Earle. 2004. Fecund gynogenic lines from onion (Allium cepa L.) breeding materials. Plant Sci. 167:1055-1066.

Bouché, F., D.P. Woods, and R.M. Amasino. 2017. Winter memory throughout the plant kingdom: Different paths to flowering. Plant Physiol. 173:27-35.

Brewster, J.L. 1983. Effects of photoperiod, nitrogen nutrition and temperature on inflorescence initiation and development in onion (Allium cepa L.). Ann. Bot. 51:429-440.

Carter, C.E., M.D. Partis, and B. Thomas. 1999. The expression of histone 2A in onion (Allium cepa) during the onset of dormancy, storage and emergence from dormancy. New Phytol. 143:461-470.

Chouard, P. 1960. Vernalization and its relations to dormancy. Annu. Rev. Plant Physiol. 11:191-238.

Currah, L. and F.J. Proctor. 1990. Seed production in tropical onions, p. 91-98. In: Onions in tropical regions. Natural Resources Inst. Bull. no. 35 .

Davie, M. 2017. National potato and onion report. 13 Feb. 2017. $<$ http://www.marketnews.usda.gov/mnp/fv-home $>$.

FAO. 2014. FAOSTAT crops data. 27 Nov. 2017. <http://www.fao. org/faostat/en/\#data/QC>.

Gorski, T. 1980. Annual cycle of the red and far red radiation. Int. J. Biometeorol. 24:361-365.

Heath, O.V.S. 1945. Formative effects of environmental factors as exemplified in the development of the onion plant. Nature 155:623-626.

Holdsworth, M. and O.V.S. Heath. 1950. Studies in the physiology of the onion plant IV: The influence of day-length and temperature on the flowering of the onion plant. J. Expt. Bot. $1: 353-375$.

Khokhar, K.M. 2014. Flowering and seed development in onion: A review. Open Access Library J. 1:e1049.

Lee, R., S. Baldwin, F. Kenel, J.A. McCallum, and R.C. Macknight. 2013. FLOWERING LOCUS T genes control onion bulb formation and flowering. Nat. Commun. 4:2884.

Lucier, G. 2011. U.S. onion statistics. 18 Jan. 2017. $<$ http://usda.mannlib. cornell.edu/MannUsda/viewDocumentInfo.do?documentID=1396>

Rabinowitch, H.D. 1985. Onions and other edible alliums, p. 398-409. In: A.H. Halevy (ed.). Handbook of flowering. Vol. 1. CRC Press, Boca Raton, FL.

R Development Core Team. 2018. R: A language and environment for statistical computing. R Foundation for Statistical Computing. Vienna, Austria. $<$ https://www.R-project.org $>$.

Serra, A.B. and L. Currah. 2002. Agronomy of onions, p. 187-232. In: H.D. Rabinowitch and L. Currah (eds.). Allium crop science: Recent advances. CAB International, New York, NY.

Shishido, Y. and T. Saito. 1976. Studies on the flower bud formation in onion plants III: Effects of physiological conditions on the low temperature induction of flower buds on green plants. J. Jpn. Soc. Hort. Sci. 45:160-167.

Shishido, Y. and T. Saito. 1977. Studies on the flower bud formation in onion plants III: Effects of physiological conditions on the low temperature induction of flower buds in bulbs. J. Jpn. Soc. Hort. Sci. 46:310-316.

Streck, N.A. 2003. A vernalization model in onion (Allium cepa L.). Rev. Brasil. Agrociência 9:99-105.

U.S. Department of Agriculture. 2016. Vegetables 2015 summary. 18 Jan. 2017. <https://doi.org/ISSN:0884-6413>.

Wiebe, H.J. 1990. Vernalization of vegetable crops: A review. Acta Hort. 267:323-328. 